\title{
REFLEXÕES SOBRE A TRAJETÓRIA ESTÉTICA DE JOÃO ANZANELLO CARRASCOZA E A FORMAÇÃO DE LEITORES LITERÁRIOS ${ }^{1}$
}

Thyago Madeira França (UEG)

Resumo: João Anzanello Carrascoza é um autor contemporâneo que apresenta um profundo comprometimento com uma linguagem sensível e sofisticada para narrar, por vezes, experiências marcantes e pungentes que atravessam a vida cotidiana do núcleo familiar, como a convivência entre pais e filhos, as descobertas, as dores e as perdas que interpelam esse cotidiano. A partir disso, proponho refletir sobre os caminhos de uma trajetória estética que perpassa as narrativas de Carrascoza, buscando demonstrar que há pontos de diálogo e convergência que percorrem várias narrativas do autor e que fazem emergir uma identidade estética carrascoziana. Busco ainda identificar as potencialidades didático-pedagógicas de tais textos em situações de formação de leitores literários no ambiente escolar, como forma de valorizar a escrita contemporânea de um autor que toca em questões que constituem a vida de todos, inclusive dos alunos-leitores inscritos em ambientes escolares que, em muitos casos, têm acesso ao texto literário por meio de práticas de escolarização equivocadas.

Palavras-chave: João Anzanello Carrascoza; Literatura brasileira; Letramento literário; Formação de leitores.

Abstract: João Anzanello Carrascoza is a contemporary author who presents a deep commitment to a sensitive and sophisticated language to narrate, sometimes, remarkable and poignant experiences that cross the daily life of the family nucleus, like living together between parents and children, the discoveries, pains and losses that challenge this daily life. From this I propose to reflect on the paths of an aesthetic trajectory that runs through the Carrascoza narratives, seeking to demonstrate that there are points of dialogues and convergence that run through various narratives of the author and that bring up a carrascoziana aesthetic identity. I also seek to identify on the didactic-pedagogical potentialities of such texts in situations of formation literary readers

1 Título em inglês: "Reflections On The Aesthetic Path Of João Anzanello Carrascoza And The Formation Of Literary Readers". 
in the school environment, as way of valuing the contemporary writing of an author who touches on issues that constitute everyone's life, including enrolled students-readers in school environments, that, in many cases, have access to the literary text through wrong schooling practices.

Keywords: João Anzanello Carrascoza; Brazilian literature; Literary Literacy; Formation readers.

\section{INTRODUÇÃO}

João Anzanello Carrascoza é um autor contemporâneo que apresenta em sua escrita um profundo comprometimento com uma linguagem sensível e sofisticada. De forma sutil, o autor esquadrinha reflexões sobre a vida, por meio de diálogos sobre a comunhão com o outro, sobre o amor e as perdas relacionadas a ele. Nesse contexto, ao construir narrativas que apresentam experiências sobre o cotidiano do núcleo familiar, Carrascoza revela a casa como um espaço de afetos e propõe um olhar microscópico para acontecimentos prosaicos que possuem, em seu âmago, uma beleza memorável.

Compreendo que abreviar a trajetória estética da escrita de um autor a uma lista de temas ou espaços é uma atitude de pesquisa irresponsável. Entretanto, o foco aqui não é obliterar sua produção em temas, mas reconhecer que existe uma identidade em sua escrita, que há convergências dialógicas no universo estético de sua produção literária, inclusive que 
permitem a reflexão sobre as potencialidades dessa escrita para a formação de uma sensibilidade humanista no leitor literário em ambiente escolar.

Além de contribuir para a fortuna crítica sobre a escrita de Carrascoza, busco reconhecer os pontos de convergência de sua produção literária como forma de propor e desenvolver práticas de letramento literário que, como propõe Cosson (2006), sejam planejadas com foco em assegurar o efetivo domínio da escrita literária, por meio de textos e processos de escolarização que, como postula Candido (2011), respeitem o direito inalienável de acesso à fruição da arte e à literatura.

De um incômodo frente aos caminhos trilhados pela literatura na escola é que surgem as reflexões que aqui empreendo sobre a obra de Carrascoza, tomada como um colírio para uma realidade escolar excludente e pouco produtiva. É evidente que os problemas que gravitam em torno do ensino de literatura são vários, no entanto prefiro me ater às possibilidades que a escrita carrascoziana apresenta para que os alunos-leitores compreendam a leitura literária como uma experiência que diz muito sobre eles e sobre o mundo em que vivem.

Ao lançar um olhar para a vida familiar e seus espaços privados, o autor escava as miudezas da convivência entre 
pais e filhos, bem como lança um olhar para as descobertas da infância, com atenção especial para as dores, os silêncios e as perdas que interpelam esse cotidiano. Parto agora para um vislumbre mais atencioso dessa sensibilidade cirúrgica de Carrascoza, de modo a reconhecer, no cerne de seus textos, diálogos que constituem um universo estético carrascoziano.

\section{REFLEXÕES SOBRE A TRAJETÓRIA ESTÉTICA DE CARRASCOZA}

Nascido no interior do estado de São Paulo, na cidade de Cravinhos, Carrascoza possui uma rica produção de contos, como seu primeiro livro Hotel solidão (1994), O vaso azul (1998), Duas tardes (2002), Dias raros (2004), O volume do silêncio (2006), vencedor do Prêmio Jabuti, Espinhos e alfinetes (2010), por muitos considerada a obra que confirma o autor como um grande nome da literatura contemporânea, Amores mínimos (2011) e Aquela água toda (2012), ganhador do prêmio APCA. Além de uma produção infantil e juvenil, Carrascoza publicou seu primeiro romance em 2013, Dos 7 aos 40 e, em 2019, seu mais recente romance Elegia do irmão.

Opto aqui por fazer uma seleção responsável e representativa da produção de Carrascoza, de modo a elucidar convergências que me permitam, por meio de um 
gesto de interpretação de pesquisador, reconhecer uma trajetória estética em diálogo no interior de seus escritos. Assim, lanço um olhar analítico para as narrativas, de modo a reconhecer a proposta de contemplação do mundo de Carrascoza, a qual, acredito, deve figurar enquanto um saber disponível aos alunos-leitores da escola pública.

Em O menino e o pião (Duas tardes), narra-se a história de um garoto que sente, ao final da tarde, a diária ansiedade pelo retorno de seu pai do trabalho. No conto, é possível perceber como a singeleza do cotidiano é representada de forma atenciosa: "Como foi o dia hoje, filho?, e ele se põe a contar tudo, o que aprendeu na escola, o gol que fez no jogo com os amigos, a lição de casa que a mãe o ajudou a fazer, uma porção de coisas que à primeira vista parecem mínimas" (CARRASCOZA, 2002, p.14). Assim, as minúcias do jantar em família, a relação de carinho entre eles e a inexorável certeza de que um dia não estarão mais juntos são elementos que produzem na narrativa uma reflexão aguçada sobre como pequenos episódios da vida devem ser valorizados como especiais e memoráveis. Aqui, e em vários textos do autor, a infância é retratada como uma fase em que se contempla a felicidade de forma mais intensa e plena, porém é um momento difuso, de muita incompreensão e aprendizado: 
"Mantém-se ali, agachado, numa felicidade que é quase insuportável de se provar em largos sorvos, tem é de fazê-lo em goles mínimos" (CARRASCOZA, 2002, p.17).

Em Cidade-Mundo (Dias raros), conta-se a história de um menino que vai viajar, pela primeira vez para a cidade grande onde moram seus tios e prima. A viagem, temática recorrente em outros textos do autor, é como uma jornada dolorosa de descobrimento do novo, do inusitado: "E agora iam eles, mãe e filho, e entre ambos, apertada, a felicidade do menino, temendo alargar-se, balão não de todo inflado pela ameaça de explodir" (CARRASCOZA, 2017, p.12). De forma quase arqueológica, o texto imprime lirismo e propõe pílulas de felicidade para uma simples viagem em família, ao demonstrar que cada elemento, as construções na estrada, os passeios, as dores da primeira paixão pela prima, enfim, as novas conquistas e descobertas são elementos que descortinam um mundo novo de possibilidades para o menino: "Um mundo que ele ia descobrindo não de longe, nem de perto, mas de dentro, e aos poucos, feliz, feliz, o menino, a abrir também suas ruazinhas e avenidas para ela" (CARRASCOZA, 2017, p.16).

Igualmente em Dias raros (Dias raros), que também há a história de uma criança que é retirada da zona de conforto 
do seu lar para um mundo de descobertas na casa da avó. "Haviam-no arrancado de seu mundo - pequenino, quando nele; e, agora, imenso, pela saudade" (CARRASCOZA, 2017, p.134). Nesses contos, a jornada de saída do casulo propõe uma metamorfose, constituída por uma primeira etapa de resistência e frustração frente ao desconhecido. Essa ruptura é seguida de uma descoberta do novo, que desabrocha numa nova felicidade: "Não lhe doía mais estar ali" (CARRASCOZA, 2017, p.134). No entanto, a dor retorna quando o novo, agora amado, lhe é retirado de forma abrupta, como se o mundo mostrasse que a felicidade na vida se dá em dias raros e poucos: "Era aquilo. Sempre uma ida às coisas e sua sequente despedida" (CARRASCOZA, 2017, p.134).

Há uma atmosfera semelhante em Aqui perto (Espinhos e alfinetes), conto em que também se apresenta a primeira viagem de um garoto que não estava preparado para sair da segurança de sua casa: "Se viver pedia larguezas ao menino, doía tudo o que nele aumentava. Por isso, quando no jantar soube da viagem, entristeceu-se, até o fundo" (CARRASCOZA, 2010, p.95). Após seus pais combinarem com os tios as férias do garoto, instaura-se um estranhamento frente ao novo que, igualmente, depois das descobertas, é substituído por uma felicidade intensa: "O menino ia vivendo o que tinha de ser, e via no sorriso do tio o da mãe, 
e se esquecia, levemente, de suas dores, sentindo que era bom estar ali" (CARRASCOZA, 2010, p.97). Portanto, nessas narrativas de descobertas da/na infância, a criança sofre com a novidade, mas também, após se adaptar, sofre com a descoberta da finitude dos momentos raros: "O pai chegou, rodeado de sol. O menino não se reanimou ao vê-lo. Não entendia seus próprios sentimentos. Nem queria. Entrou no carro. Acenou para todos à porta da casa. Ele novamente se partia..." (CARRASCOZA, 2010, p.101).

Outra atmosfera temática que gravita em torno da infância nos contos é o enfrentamento da morte de um ente querido. Em Chamada (Dias raros), há a história de uma criança que sofre por uma séria doença que acometeu sua mãe. O conto passeia pelo espaço da escola, onde todos já sabem do sério estado de saúde de sua mãe: "Era assim, alguém sempre queria saber como andava sua mãe, e ela se aborrecia com a curiosidade alheia" (CARRASCOZA, 2017, p.22), e é justamente a dificuldade de lidar com o incompreendido luto que causa uma ruptura, seguida de um melancólico aprendizado frente à situação de morte: “Atravessaram a rua ensolarada e seguiram pela avenida principal, silenciosos, à sombra das grandes árvores. E, antes que o pai lhe dissesse o que tinha a dizer, ela compreendeu tudo" (CARRASCOZA, 2017, p.22). 
Em Espinho (Espinhos e alfinetes), em tom de reminiscências, um homem retoma a sua infância vivida ao lado do irmão mais velho André, pessoa que the proporcionava as descobertas do mundo. André era sábio, feito uma estrada para a contemplação e aprendizado sobre as singularidades da vida: "tudo eu entendia menor, e ele me ajudava a aumentar" (CARRASCOZA, 2010, p.11). Era o irmão quem lhe ensinava a fazer a leitura mais bela e sensível do mundo bucólico que os constituía: “Com André o mundo se mostrava em novidades, o mundo acordava, e os dias, qualquer um e todos, eram dias de lembrar o que os olhos esqueciam no costume de ver demais" (CARRASCOZA, 2010, p.10). Após o adoecimento misterioso de André, os pais retornam do hospital abatidos com a trágica e silenciosa notícia de sua morte: "Sem o André, quem iria me ajudar a ver aquela imensidão?" (CARRASCOZA, 2010, p.16).

Semelhante atmosfera se apresenta em Mundo Justo (Aquela água toda), em que o personagem narra sua infância como atleta de basquete e sua relação com o irmão mais novo Edu. Além de uma profunda relação de aprendizado com os ensinamentos do treinador Urso, o personagem reforça o interesse e apoio incondicional que seu irmão Edu lhe dava, sempre disposto a incentivar a sua conquista pessoal: 
Edu não só perguntava, o Edu torcia, ele alegre se eu alegre, ele me consolando se eu desanimado, o Edu, apesar de mais novo, já sabia antes de mim, não tenho dúvida, aquela lei estava acima das outras, da gravidade, da termodinâmica, de todas, o Edu, de tanto se enfurnar naqueles livros, sabia me ler, letra por letra. (CARRASCOZA, 2018, p.54)

Feito André de Espinho, Edu também é a referência de aprendizado do irmão. Novamente a narrativa vai se apresentando sob o ponto de vista da criança e, à conta-gotas, instaura o ambiente da dor pela perda, em que a criança precisa aprender a lidar com o luto. Com um semelhante desfecho, Edu morre atropelado por um trem, deixando seu irmão sem sua referência pessoal para as aprendizagens do cotidiano. A morte de uma pessoa querida, seguida de um processo de aprendizado pelo luto, emerge como um elemento temático recorrente nos textos do autor.

Na obra Espinhos e alfinetes, além de Espinho, há irmãos que sofrem a antecipação da morte iminente de sua irmã doente em Dora; um pai e um filho que precisam aprender a viver sem a presença da esposa-mãe recém-falecida em Alfinete; um neto adulto que chora a morte iminente da sua avó que o criou; um filho que relembra o pai morto por um ataque cardíaco em Coração; um pai que chora a perda do filho afogado em Mar. 
Em estudos realizados em França (2017), estabeleci que, nos contos da referida obra, a morte se apresenta como uma epifania que causa a ruptura com a normalidade banal e chacoalha o cotidiano das personagens, elucidando, por meio da dor pela perda, uma realidade melancólica e inevitável, ou seja, a revelação sobre a efemeridade da vida. Isso não representa dizer que Carrascoza tematiza a morte como nuclear, mas que ela é revelada por meio dos vestígios de vida que gravitam em torno desse acontecimento. A morte, dessa forma, é elucidada como proposta de reflexão sobre a vida, acontecimento que leva a um amadurecimento do eu.

Para além das diversas formas de luto que se revelam em seus contos, as narrativas carrascozianas também apresentam como diálogo estético-discursivo um delinear de retratos de um cotidiano tão simplório, que choca pela beleza raramente percebida. Aqui não são grandes acontecimentos que geram, necessariamente, rupturas afetivas, mas de situações prosaicas, elaboradas de forma sutil e poética, por meio de personagens sensivelmente atentos. É o que acontece em Passeio (Aquela água toda), em que o pai revela aos filhos um passeio surpresa para o sábado de manhã. As crianças quase não dormem de ansiedade e emoção pelo enigmático passeio: "O que seria? O passeio, misterioso! Mas como são 
grossas as camadas da certeza, a menina não podia penetrálas e ficou só na sua superfície, inventando lugares menores, se comparados à realidade" (CARRASCOZA, 2018, p.68).

No dia seguinte, a família segue para o ponto de ônibus e a experiência que, diariamente, seria banal, reveste-se de uma singeleza lírica, pois o vislumbrar do próprio bairro, dos comércios, das praças, do tráfego nas grandes avenidas se torna um acontecimento luminoso e inesquecível: "Aí foram dar numa avenida de tráfego veloz, depois passaram por uns bairros bonitos; parecia outra cidade" (CARRASCOZA, 2018, p.72). Quando o ônibus chega próximo ao aeroporto, as crianças compreendem e se maravilham com a oportunidade de conhecer aquele lugar e suas aeronaves. Eles não estavam ali para viajar de avião, mas para contemplar a grandiosidade daquelas máquinas que fazem o homem voar:

Dali, podiam avistar a entrada principal do aeroporto, a torre de controle, um trecho da pista onde um avião taxiava lentamente, sem que soubessem se era sua partida ou chegada. Também não importava: só queriam vê-lo, com os olhos da certeza, aquele era o instante, sem o antes e o depois, o imediato real. (CARRASCOZA, 2018, p.73)

A alegria das crianças ao conhecerem o aeroporto alcança o seu clímax quando contemplam o pouso de uma aeronave: "Olha lá, olha lá!. Chegava, enfim, a hora máxima" 
(CARRASCOZA, 2018, p.74). Novamente o autor permite uma reflexão sobre a vida a partir de um acontecimento simples, porém majestoso e memorável àquelas crianças. É como se Carrascoza buscasse causar um constrangimento construtivo àqueles que não são capazes de enxergar a felicidade em situações corriqueiras.

Também sob a ótica de uma admirável leitura do corriqueiro, no conto Domingo (Amores mínimos) narrase um encontro dominical entre familiares e seus filhos. Baseado numa rotina contemplada em seus detalhes, o narrador imagina a chegada de cada um dos membros da família, ao retomar seus conhecidos itinerários e hábitos: "Depois, seria a vez de Pedro e a menina, os dois quase não falavam, às vezes doía ouvir o silêncio deles" e "Logo saberíamos, pelo latido dos cachorros, que Marcos tinha chegado" (CARRASCOZA, 2011, p.79).

Já em Só uma corrida (Espinhos e alfinetes) e em Escolar (Amores mínimos), apresenta-se a figura metafórica de motoristas que, durante o exercício de seu labor, constroem reflexões melancólicas sobre a vida. Só uma corrida traz a figura de um taxista de meia idade que narra suas histórias de vida enquanto dirige: "É só uma corrida, melhor que seja confortável, trajeto curto ou longo, o que importa é a gente fazer a viagem em paz" (CARRASCOZA, 2010, p.105). 
Numa dada corrida, o motorista se depara com um passageiro introspectivo e silencioso que, repentinamente começa a chorar. O choro do passageiro e os eventuais motivos para essa reação desencadeiam reflexões no motorista: “Aqui dentro já teve de tudo: pedido de casamento, parto, desmaio... Mas nunca um homem chorando. Fiquei pensando no que teria acontecido com ele" (CARRASCOZA, 2010, p.106). O misterioso pranto é a epifania que desencadeia no taxista uma infinidade de memórias, uma vez que, ao se emocionar com a situação, ele passa a relembrar vários momentos que, embora banais, figuram como emblemáticos em sua vida, momentos esses facilmente escamoteáveis ao esquecimento frente à intensa rotina dos dias atuais.

Valendo-se da metáfora da vida como uma corrida de táxi, o motorista remonta vários episódios que constituem sua vida, ao se recordar da convivência com os seus pais já falecidos, do cachorro de infância sacrificado, de sua namorada de adolescência e do grande amor do passado. Enfim, trivialidades que o constituem enquanto um produto de sua história: "Lembrei de outras alegrias, o último aniversário da mãe, com todos os parentes ao redor, até meu irmão veio do estrangeiro; lembrei da lua naquela noite em Cravinhos com Maria Cândida" (CARRASCOZA, 2010, p.109). 
De forma semelhante, Escolar narra as reflexões de um motorista de van escolar, que reflete sobre a singeleza e as sensações que constituem o seu diário trabalho de transportar com segurança os filhos de outras pessoas para a escola: "Pegaram logo suas vidas, como as mochilas, e, com os olhos ainda sujos de espanto, saíram à rua e entraram na van escolar, onde seguem comigo" (CARRASCOZA, 2011, p.15). Como o taxista, o homem enxerga a alegoria da vida em seu labor: "A vida é aos trechos, e eu só as conduzo, nessas manhãs, por um curto trajeto, umas ruas caldas que desembocam em avenidas estridentes, até que alcancemos os portões do colégio" (CARRASCOZA, 2011, p.16).

Assim, ainda que demonstre, de forma melancólica, ter a consciência de que um motorista de van é um profissional "esquecível" na vida de uma criança, ele igualmente sabe da grandeza de sua missão, a de transportar as crianças com segurança. E esse momento de reflexão faz com que ele se reconheça como parte da construção das histórias de vidas delas: "Estamos chegando, crianças, e nesse sorriso, eu bem sei, é que se esconde a minha lição de vida" (CARRASCOZA, 2011, p.18).

No conto Ali (Dias raros), narra-se um encontro de família que acontece em um sítio, a partir das lentes que potencializam a beleza que circundam os silêncios 
constrangidos de uma reunião familiar: "Era sábado e eles haviam acordado cedo. Uma expectativa silenciosa os movia, o encontro com a família a duzentos quilômetros da cidade onde residiam" (CARRASCOZA, 2017, p.93). Dessa forma, é a inquietação pela chegada que interpela a família urbana e que dá a tônica afetiva e singela do conto, a qual deseja estar o quanto antes no sítio de seus parentes.

Assim, imaginar a viagem pela rodovia, as paisagens transcorridas, o encontro com o amado irmão, a euforia dos cachorros do sítio, os abraços e beijos de chegada, contagiam o pai da família, que já se alegrava por antecipação, por poder confraternizar com aqueles que the constituem enquanto parte de um todo: "Vieram os abraços, os beijos, contidos, é verdade, eles se gostam sem exibições ostensivas de afeto, preferem o quieto contato das almas" (CARRASCOZA, 2017, p.95).

Ao delinear com percepção lírica e cirúrgica os silêncios constrangidos entre as personagens, o autor faz transbordar um cotidiano brilhante e memorável, repleto de vestígios de afeto e carinho: "De um irmão para o outro voavam uns assuntos comuns, Como andam as coisas?, E os negócios?, degraus para se chegar àquilo que não sabiam verbalizar, mas apenas sentir calados" (CARRASCOZA, 2017, p.96). 
Além dessa notória regularidade de vozes que atravessam e constituem os contos de Carrascoza, cito também dois de seus romances, o primeiro, Aos 7 e aos 40, e o mais recente Elegia do irmão. O seu primeiro romance apresenta a história de vida de um homem narrada em dois momentos, a infância e a meia-idade, de modo que os capítulos se intercalam entre memórias da meninice e reflexões da vida adulta que, ao final, costuram-se como as duas metades indivisíveis de uma história. Assim, sua vida de criança, seus amores, o casamento, o nascimento de seu filho, o divórcio e outras reflexões vão sendo apresentadas num batimento histórico, para que o leitor reconheça as nuances de um no outro, do menino no homem: "Mas, se reconhecera aquele que à sua frente aparecia, alguns traços eram idênticos aos seus - outros, menos aparentes, da mãe -, surpreendeu-se ao flagrar no menino, nitidamente, o homem que nele se prenunciava" (CARRASCOZA, 2013, p.106).

De forma pungente e melancólica, o texto reforça como existe uma distância irrecuperável entre as fases da vida, além de propor a ideia de como, imperceptivelmente, nos transformamos no que somos a partir de fatos, experiências e acontecimentos relativamente esquecíveis, os quais acabam sempre por reverberar em nossa trajetória de existência. 
Dou atenção especial à questão do casamento em ruínas que, aos olhos do narrador, vai se esvaindo em pequenas e imperceptíveis atitudes desatentas, porém destrutivas para um relacionamento: "Sabia, era uma certeza visceral, que o seu time havia ganho o campeonato, - e sabia, também, mirando pelo retrovisor o vulto único no banco de trás, que uma perda, lá adiante, o esperava" (CARRASCOZA, 2013, p.45).

Abro aqui um adendo para me referir a três outras narrativas do autor que tomam o divórcio e a relação entre pais divorciados e filhos. O final de um casamento é uma perda que gera um luto e, nesses textos, o autor trata do tema de forma delicada, demonstrando como, por vezes, são as vaidades e as intransigências que fazem ruir os castelos. Poente (Espinhos e alfinetes) é sobre a morte simbólica de um casamento e apresenta o diálogo final entre o casal. 0 título do conto dialoga com o apagar do calor e do afeto que o casamento tinha como proposta de construção da família. Como o sol que se põe, também o casamento estava ao fim: "O homem ergueu a cabeça e sussurrou, Não pensei que fosse acabar assim; a mulher, os lábios trêmulos, ia dizer, Não pensei que fosse acabar, mas engoliu seu desencanto e não disse nada" (CARRASCOZA, 2010, p.29). Após um frio e monossilábico diálogo, o casal percebe que não há mais 
esperanças, restando somente dar a triste notícia ao filho: " $E$ o menino? Quando contamos a ele? O homem viu pela janela a paisagem estourada de luz. Ja!, respondeu, pra que adiar?" (CARRASCOZA, 2010, p.34).

Em $A$ hora (Amores mínimos), narra-se a convivência telefônica diária entre um pai e um filho. As ligações de segunda a sexta eram religiosamente sagradas e importantes para o filho: "No entanto, bastava o telefone tocar, à noite, para eu sofrer aquele susto bom, e, quando a mãe me passava o telefone, nem precisava dizer, É o seu pai" (CARRASCOZA, 2011, p.48). Em tom de reminiscências, o filho já adulto lembra como seu pai, agora falecido, não o abandonara em nenhuma das fases de sua vida, inclusive nos momentos de rebeldia da adolescência: "Recusei-me muitas vezes a falar com ele, surdo para a mãe que vinha bater à porta do quarto, Atende, é o seu pai" (CARRASCOZA, 2011, p.48).

Em um contexto semelhante, o conto Porta (Amores mínimos) narra o breve momento de contemplação de um pai que, pela sacada de seu apartamento, observa atentamente, semanalmente, a chegada de seu filho para visitá-lo, desde a descida do carro da mãe até a batida na porta de sua casa: "Como sabia a hora em que ele ia chegar, saí à sacada do apartamento e mirei lá embaixo a linha das casas, a rua em frente ao prédio onde o carro dela o deixaria" 
(CARRASCOZA, 2011, p.83). O conto se constrói nesse processo de contemplação, de forma a reforçar as zonas de silêncio que existem em torno do amor que o pai tinha pelo filho, o qual aproveita até os segundos de sua chegada de uma forma que somente ele tinha o prazer de contemplar, lá do alto: "Contemplei-o lá de cima e experimentei uma ternura tão forte que temi ser vítima, em breve, de uma dor na mesma medida" (CARRASCOZA, 2011, p.85).

Nesses textos, Carrascoza imprime singeleza e afeto nas relações entre filhos e pais divorciados, demonstrando como o luto do casamento e a distância geográfica inevitável não silenciam a celebração do amor paterno, por vezes desmerecido nos dias atuais. Retomo Aos 7 e aos 40 justamente para demonstrar essa reconstrução de uma relação entre pai e filho, que agora terão de edificar uma nova rotina para enfrentar as saudades face aos encontros somente de final de semana: "Aquele dia, que antes era uma promessa, agora fabricava a realidade no pai, ele flamejava, por ter junto de si o filho, íntegro, raiando depois de sua muita ausência" (CARRASCOZA, 2013, p.109).

O romance Elegia do irmão também é dividido em duas partes, sendo elas "Um pouco antes" e "Um pouco depois". O romance conta a história de Mara a partir das memórias 
de seu irmão. Diagnosticada com uma doença grave que a levará à morte, Mara passa por um complicado período de tratamento e, em decorrência dessa dor, seu irmão passa a reviver e a reconstruir os passos vividos ao lado de sua irmã.

Como toda elegia, o romance é o prenúncio da morte de Mara. Assim, por meio de capítulos curtos e fúnebres, o irmão revive a infância, a adolescência e a vida adulta compartilhada com Mara, como forma de homenagear a sua irmã condenada a perecer ainda tão jovem: "Penso nas conversas que tivemos, quando parecia que não morreríamos. Mas ela se foi. E eu fiquei. Viver mais significa não só vida mais longa, mas também morrer mais. Minha irmã morreu menos" (CARRASCOZA, 2019, p.113-114).

Para o irmão, essas feridas têm dono, ele tem o direito de viver cada segundo do sofrimento de estar ao lado de uma irmã condenada à morte. Entendo que o romance consolida a temática do amor fraterno como uma das ligações mais profundas, fazendo com que esse tema se cristalize e emerja como singularidade em Carrascoza: "O seu nome, Mara, quando dito, até mesmo pensado, o seu nome a cristaliza dentro de mim, disparando um sem-número de sensações, plácidas e convulsas - é o tônus da vida, a contenção do expandido, a expansão do contido" (CARRASCOZA, 2019, p.17). 
O autor já havia mobilizado a irmandade em outras narrativas, como em Espinho e em Dora (Espinhos e alfinetes), já citados anteriormente, e em Janelas (Dias raros), conto em que o irmão faz uma visita repentina à sua irmã, a qual se sente constrangida de não se mostrar forte e feliz, por estar passando por diversos problemas: "Estremeceu ao dar com o irmão ali, aureolado de sol, o semblante sereno, um sorriso a Ihe escapar dos lábios, surpresa tanto quanto em menina, mas agora sem ter o que atirar nele senão o seu espanto. Você, aqui!" (CARRASCOZA, 2017, p.106).

Na narrativa, o silêncio das personagens é ensurdecedor, demonstrando, como em outros contos, como a demonstração de afeto, por vezes, gera constrangimento. No entanto, ainda sim, com singeleza e suavidade, o texto reforça o quanto ligações como o amor fraterno estão para além de uma linguagem verbal objetiva. É como se os silêncios bastassem para exprimir que 'eu sou seu irmão' e 'você é minha irmã': "Mas em vez de ela dizer, Que bom que você veio, sou tão sozinha, e ele, O que você está me escondendo?, deram para falar dos outros, era um subterfúgio, uma forma indireta de falarem de si" (CARRASCOZA, 2017, p.107).

Retorno à Elegia do irmão para ressaltar que Carrascoza não somente consolida o diálogo com o amor fraterno, tema 
tão escasso na literatura universal, como também reforça que as reminiscências dos fatos passados representam mais que a nostalgia dos bons tempos, uma vez que também renovam as dores, revivem o luto e chancelam a impotência humana frente a situações inevitáveis: "Nenhuma morte é edificante, nenhuma morte nos propicia a compreensão do mistério, nem reduz a distância entre nós e o céu. O sofrimento originário de uma perda, não nos ensina lição alguma, só nos arrasa ainda mais" (CARRASCOZA, 2017, p.146).

Em diálogo com esse olhar minucioso e reflexivo para o cotidiano familiar, é importante reforçar o caráter memorialista que atravessa e constitui a trajetória estética de Carrascoza. Muitos de seus textos são, como propõe Conde (2009), como dípticos em que a dramaticidade se dá no contraste entre um antes e um depois, com a narração situada em um desses pólos, ou seja, "ora é uma cena da infância que é apresentada já como passado de um futuro apenas pressentido, ora é um momento da vida adulta que é comparado a uma memória antiga" (CONDE, 2009, p.228).

Essa característica pôde ser percebida em muitos textos do autor. A memória da personagem instaura processos reflexivos por meio de lembranças e releituras de tempos vividos, ou ainda por meio de lutos antecipados, face a 
mudanças, aprendizados e mortes iminentes. Em Elegia do irmão, Carrascoza revisita e chancela sua concepção de memória, presente em grande parte de sua escrita: "A memória, como rede de arrasto, a memória, as linhas entrançadas e bem urdidas aos vazios, a memória, os nós para prender, as lacunas para escapar, a memória" (CARRASCOZA, 2019, p.93).

A memória, então, é responsável, ao mesmo tempo, por permitir a lembrança dos amores e dores vividas, mas também por fazer doer, ao não deixar esquecer das perdas, ao afirmar que a morte, a dor, a distância e a separação são névoas inevitáveis que fazem parte da vida. Com essa visão, o autor propõe a celebração das sutilezas, das ternuras, dos amores mínimos, das nuances poéticas que interpelam os espinhos e os alfinetes que nos ferem, para que possamos refletir, perceber a beleza de coisas que geralmente não damos atenção e reconhecer, nas perdas, estímulos para valorizar o amor.

Longe de almejar percorrer toda a produção literária carrascoziana, paro por aqui com as exemplificações e sintetizo que o autor quer nos ensinar um pouco sobre o processo de construção do eu, demonstrando-nos o quanto os encontros - pais e filhos, relacionamento amorosos, netos 
e avós, irmãos e irmãs, o presente e o passado - asseveram a inexorável certeza de que as distâncias e as dores se renovam e são partes necessárias da nossa existência.

\section{LITERATURA E FORMAÇÃO DE LEITORES LITERÁRIOS NA ESCOLA}

Para estudiosos da literatura, a produção contemporânea brasileira tem dialogado, de forma contundente com representações de violência, conflitos sociais e leituras que dão voz a grupos marginalizados socialmente. No entanto, Carrascoza vai na contramão dessa tendência, ao promover sensíveis encontros afetivos entre suas personagens e 0 mundo. Sobre esse impasse, Conde (2009, p.224) postula que "suas histórias não fulminam o leitor com choques do real, sua escrita pouco encena - ou mimetiza - conflitos sociais" e que, portanto, sua obra não oferece "de imediato como um terreno dos mais férteis para os discursos críticos correntes". Assim, ao promover a leitura dos silêncios que atravessam os encontros humanos, o autor foge de uma tendência do mercado de produção literária.

No entanto, o que poderia soar como o diagnóstico de uma escrita piegas, excessivamente romântica ou deslocada dos dias atuais, emerge como um colírio, como ensaios de esperança não somente para a literatura, uma vez que a 
riqueza estética e linguística de sua prosa é inquestionável, mas também para que possamos vislumbrar leituras outras, talvez mais otimistas, para os dias de hoje.

Em França (2017), postulo que o ensino de literatura na escola pública parece se ancorar em práticas que focam no estudo da historiografia da literatura; no texto literário como parte integrante de listas de processos seletivos; em matrizes curriculares que organizam a literatura de forma histórica; no uso equivocado de fragmentos de textos literários. Aliado a esses fatores, há ainda questões excludentes relacionadas ao cânone literário escolarizado e à pouca formação nos cursos de Letras voltada para o ensino de literatura. Sintetizo esse contexto com a simples proposta de que o ensino de literatura precisa ter como mote o texto literário e sua leitura planejada e com objetivos claros. Não se trata de uma propositiva utópica.

Ao construir reflexões sobre o poder da leitura literária e as interdições culturais nos dias atuais, Petit (2009) reforça a importância de se promover a interação entre esses leitores marginalizados e o texto literário, por meio de práticas que permitam "mais do que a decodificação dos textos, mais do que a exegese erudita, o essencial da leitura era, ao que parecia, esse trabalho de pensar, de devaneio" (PETIT, 2009, 
p.24). A autora ainda postula como práticas produtivas de leitura têm o poder de fazer com que esses sujeitos tenham a possibilidade de transgredir, de modo a se livrar das "imposições sociais e se apropriar dos lugares e dos objetos que não eram destinados a eles" (PETIT, 2009, p.44).

Da mesma forma, Candido (2011) estabelece que o acesso à literatura no Brasil dialoga com as diferenças de classe, ou seja, o autor reforça que existe uma segregação das oportunidades culturais em nosso país: "numa sociedade estratificada deste tipo a fruição da literatura se estratifica de maneira abrupta e alienante" (CANDIDO, 2011, p.187). Logo, é naturalizado que o filho da classe trabalhadora não precisa ter acesso à arte e à cultura, devendo aprender somente um ofício técnico que the garanta emprego e sobrevivência.

A escola deve buscar formas de promover uma competência literária responsiva, por meio de uma ampliação progressiva do repertório de leituras literárias, que thes apresentem variados mundos de linguagem, mas que também humanizem, que mobilizem temas e valores que, na sociedade, podem ser negados, combatidos e defendidos. Compreender esses discursos acontecendo no texto literário é uma importante estratégia para a formação de leitores literários que sejam capazes de apurar uma inteligência 
sutil e crítica, de modo a "explorar a experiência humana, atribuindo-Ihe sentido e valor poéticos" (PETIT, 2010, p.29).

Entendo que a visão de um leitor com uma inteligência sutil para a leitura das experiências humanas se aproxima do que Candido propôs como humanização, processo que chancela no homem traços essenciais como o exercício "da reflexão, a aquisição do saber, a boa disposição para com o próximo, o afinamento das emoções, a capacidade de penetrar nos problemas da vida, o senso da beleza, a percepção da complexidade do mundo e dos seres, o cultivo do humor" (CANDIDO, 2011, p.180). Nesse contexto, a experiência com a literatura na escola precisa ampliar a interação dos alunos com os mundos ficcionais, para que esses possam ser capazes de refletir e, se necessário, de enfrentar uma infinidade de questões inerentes à natureza humana (a perda, a morte, os conflitos, os amores).

Por isso combato a escolarização restritiva da literatura, encabeçada por profissionais que, para Paulino (2013), nem sempre são leitores e não desenvolveram a cidadania literariamente letrada. Essas práticas equivocadas “distanciam-se de comportamentos próprios da leitura literária, assumindo objetivos práticos, que passam da morfologia à ortografia sem qualquer mal-estar" (PAULINO, 2013, p.19). 
Petit (2010, p.55-56) diz que a ficção literária é transmitida para a criança (o leitor) de forma a alimentar o seu pensamento e permitir que ela reflita e enfrente as grandes "questões humanas, tanto quanto possível (os mistérios da vida e da morte, da diferença entre os sexos, o medo do abandono, do desconhecido, o amor, a rivalidade etc.); e para celebrar a vida cotidiana". Nessa seara, entendo ser notório como a escrita de Carrascoza parece permitir uma interação sutil e poética do leitor com essa celebração da vida, humanizando e formando leitores. Compreendo que um autor pode provocar efeitos diferentes em leitores diferentes. No entanto, o caráter singelo e acessível da linguagem de Carrascoza, bem como a forma que ele propõe e metaforiza o cotidiano, oferecem caminhos produtivos para a formação de jovens leitores literários no âmbito da escola.

\section{PRÁTICAS DE LETRAMENTO COM CARRASCOZA NA ESCOLA}

Em seus estudos sobre letramento literário, Cosson (2006) estabelece a importância de que se trabalhar com obras atuais. No entanto, o autor reforça que isso não significa priorizar escritas contemporâneas e define obras atuais como "aquelas que têm significado para mim em meu tempo, independentemente da época de sua escrita ou publicação" 
(COSSON, 2006, p.34). Compreendo que se tratam de textos que oferecem formas de ver e representar o mundo possíveis de serem acessadas pelos alunos-leitores. Por isso defendo que escritas poéticas como a de Carrascoza devem permear as práticas de salas de aula, pois seu olhar, quase atemporal, para as questões da existência tem potencial, ao mesmo tempo, de humanizar o ser e de formar o leitor.

Passo para uma descrição de experiências de letramento literário desenvolvidas em duas situações diferentes, em aulas regulares da $1 \underline{\text { a }}$ série do ensino médio e em oficinas semanais com alunos do ensino fundamental. Os resultados não descrevem as etapas das sequências básicas ou expandidas (COSSON, 2006) construídas para a execução das ações de letramento, mas sim a dinâmica fluida dos processos de interação dos alunos-leitores com as narrativas de Carrascoza.

Ao longo das práticas de letramento, utilizei três formas de interação com o texto literário, de modo que cada método de leitura apresentasse suas potencialidades e deficiências: I - leitura silenciosa, seguida de discussões direcionadas; II - leitura coletiva em que cada aluno lia um fragmento do texto, seguida de discussão direcionada; III - leitura em voz alta empreendida por mim, de forma a promover 
o desenvolvimento da capacidade de escuta, seguida de discussões. Desenvolver metodologias diferentes de leitura significou oferecer situações diversas de imersão no mundo estético dos textos de Carrascoza e também uma forma de testar caminhos para promoção de as ações de letramento literário.

As primeiras atividades nas salas de aula regulares aconteceram em três turmas da $1^{\text {a }}$ série do ensino médio ao longo de um semestre. O fator limitante de horários de cinquenta minutos levou a escolha de contos de Amores mínimos (2011), obra de narrativas curtas, de duas a três páginas. Uma escolha pragmática que partiu do contexto real da dinâmica da escola para oferecer atividades de literatura que realmente tivessem como foco a leitura e a compreensão dos sentidos. Nessas turmas, foram trabalhados três contos, Escolar, A hora, Porta. O trabalho com Escolar teve como entrada temática a questão das profissões invisíveis, de pessoas que passam pela nossa vida e acabamos por nos esquecer. Em todas as salas, houve uma participação intensa dos alunos tanto no processo de leitura, conduzido a partir dos objetivos estabelecidos, quanto nas diversas nuances do processo de interpretação.

Nas atividades desenvolvidas com $A$ hora e Porta, a entrada temática foi a relação entre pais e filhos, com 
foco nas situações que envolvem pais divorciados. Por conta de existirem vários alunos que têm pais separados, as interpretações e interações foram bem produtivas. Em algumas situações, por exemplo, os alunos-leitores mergulharam no universo estético construído pelo autor e problematizaram situações diversas sobre as atitudes e posturas expressas nas narrativas, discordam e/ou chancelando posicionamentos identificados.

Além de uma resposta positiva quanto ao processo de leitura dos contos, ou seja, os alunos conseguiram acessar os aspectos linguísticos e literários propostos pelo autor, também ressalto a surpresa de alguns alunos quanto a uma aula de literatura com textos curtos, completos, de um autor vivo, lidos e interpretados em uma aula e que tratam de temas que eles conhecem e se identificam. Alguns estranharam o formato e pensaram se tratar de um momento de recreação de leitura, ou seja, tiveram dificuldades de compreender a leitura mediada e organizada de textos literários como um processo adequado de escolarização da literatura.

Nas turmas regulares, não trabalhei somente com textos do Carrascoza e é por isso que ressalto a interação acolhedora e reflexiva que se deu com essas narrativas. Acredito que esse resultado está para além dos temas cotidianos 
comumente abordados, uma vez que há um projeto estético carrascoziano, em que elementos estruturais, rítmicos e poéticos confluem e permitem uma sofisticada interação com o leitor de várias idades.

A segunda etapa de atividades com as narrativas carrascozianas se deu por meio de oficinas semanais, com alunos do ensino fundamental e no contraturno, ou seja, diferentemente das práticas de letramento nas aulas regulares, as oficinas contaram com um público voluntário, composto por alunos que queriam participar ativamente das atividades. Assim, de um universo de turmas de vinte e poucos alunos, as oficinas contaram com um público médio de dez participantes regulares.

Os encontros semanais tiveram duração de uma hora e trinta minutos e aconteceram no espaço privilegiado da biblioteca escolar da escola pública, a qual era preparada semanalmente para o desenvolvimento das oficinas. Apesar de atingir um público menor, o formato de oficinas semanais permitiu que discutíssemos os objetivos de cada prática de letramento com os participantes, em sua maioria alunos do 7으 e 8 으 ano do ensino fundamental.

Nas oficinas, foram desenvolvidas práticas de letramento com os contos Dora, Ali, Espinho, Alfinete, Passeio, Mundo 
justo, O menino e pião e Aqui perto. Além de dialogarem com os temas anteriormente descritos, ou seja, o luto pela perda de pessoas da família, o amor fraterno, a relação entre pais e filhos e as descobertas da infância, os contos permitiram que os alunos percebessem elementos convergentes na escrita do autor. Assim, houve situações em que eles associaram características estéticas de contos já lidos ou, ainda, destacaram singularidades, como o ambiente de perda e melancolia ou o espaço das relações familiares, como marcas autorais da escrita de Carrascoza.

Outro aspecto positivo foi a identificação dos leitores com os acontecimentos presentes nos contos, o que permitiu que os encontros fossem permeados de debates diversos. Ressalto ainda que os leitores reconheceram um ritmo peculiar na escrita de Carrascoza, entendido por eles como uma espécie de identidade singular. Foi gratificante reconhecer que esse olhar atencioso para a escrita do autor também decorreu de um maior tempo de exposição aos textos e à construção de práticas planejadas, com objetivos claros, de letramento.

Os contos trabalhados na oficina foram lidos, pelo menos, duas vezes, sempre contando com uma leitura mediada em voz alta e uma segunda leitura, que alternava entre a 
silenciosa no início da atividade ou conjunta depois da primeira interpretação. Houve ainda situações em que os contos foram lidos três vezes, contemplando todos os formatos supracitados.

A escuta do texto por meio da leitura mediada permitiu que os leitores identificassem um ritmo peculiar na escrita carrascoziana. Petit (2010) reforça que, independentemente da riqueza da linguagem do texto, a leitura em voz alta de obras literárias permite uma experiência sensorial mais profunda. Para a autora, o ritmo e a musicalidade dos textos literários acolhem, ampliam a interação entre o texto e o leitor. A experiência de identificação de uma cadência rítmica carrascoziana foi vivenciada pelos alunos, inclusive ressaltada como elemento essencial para que gostassem das leituras. Em suas palavras, Carrascoza fala de forma leve sobre coisas da vida de todo mundo, inclusive sobre a morte.

Entendo que o formato da oficina, com encontros com maior duração e a composição de uma comunidade de leitores regulares, permitiu que a proposta de formação de leitores literários via Carrascoza obtivesse êxito. A escolha de um autor com uma escrita sensível também se relaciona ao desejo de que os alunos da escola pública, por vezes negligenciados pelas políticas de formação de leitores, 
contemplem facetas poéticas sobre sua existência. Em seus relatos, eles afirmam que os contos permitiram que reflexões riquíssimas sobre como algumas dores e perdas precisam ser vividas e como, no dia-a-dia, existem escondidos diversos acontecimentos que merecem atenção.

Cosson (2006, p.27) diz que, "ao ler, estou abrindo uma porta entre meu mundo e o mundo do outro". Considero que, além de demonstrar as potencialidades didáticopedagógicas da escrita carrascoziana para a formação de leitores literários na escola, as atividades desenvolvidas incitaram um olhar reflexivo dos alunos para o seu mundo e o mundo do outro.

\section{CONSIDERAÇÕES FINAIS}

Ao atribuir sutileza e sensibilidade a fatos casuais do cotidiano familiar, Carrascoza incita que o leitor seja uma pessoa melhor e que se reconheça em seus espinhos, por meio de um aprendizado indireto sobre si e sobre o outro. Propõe que celebremos a vida, que acreditemos no ser humano e no amor. Revela-nos como os acontecimentos de perda burilam o ser humano que somos. Mostra-nos como o silêncio por vezes é revelador de ternuras comumente negligenciadas. De forma otimista sobre a vida, pede-nos que reconheçamos a profundidade do convívio familiar, ao revelar os vestígios de afeto os gestos de gentileza e amor. 
Em respeito à produção viva e pulsante de Carrascoza, reforço que tão pouco esbocei alguns dos seus caminhos trilhados, por meio de gestos responsivos de interpretação analítica e relacional. Por isso, com o vislumbre de ainda muito mergulhar em sua obra, encerro com a clareza de ter apenas esboçado traços de um projeto estético de um grandioso autor. Espero que os filhos da classe trabalhadora, principal público da escola pública, não sejam cerceados do direito inalienável de acesso à literatura humanizadora de João Anzanello Carrascoza.

\section{REFERÊNCIAS}

CANDIDO, Antônio (2011). "O direito à literatura". In: Vários escritos. Rio de Janeiro: Ouro sobre Azul, p.195-216.

CARRASCOZA, João Anzanello (2019). Elegia do irmão. Rio de Janeiro: Alfaguara.

(2018). Aquela água toda. Rio de Janeiro: Alfaguara.

(2017). Dias raros. São Paulo: SESC-SP editora.

(2013). Aos 7 e aos 40. São Paulo: Cosacnaify.

(2011). Amores mínimos. Rio de Janeiro: Editora Record.

(2010). Espinhos e alfinetes. Rio de Janeiro: Editora Record.

(2002). Duas tardes. São Paulo: Editora Boitempo.

CONDE, Miguel Bezzi (2009). "A escrita comovida de João Anzanello Carrascoza." Estudos de Literatura Brasileira Contemporânea, 34, 223-232. COSSON, Rildo (2006). Letramento literário: teoria e prática. São Paulo: Contexto.

FRANÇA, Thyago Madeira (2017). A discursividade literária em João Anzanello Carrascoza - por uma episteme do ensino de literatura. 
228f. (Tese - Doutorado em Estudos Linguísticos). Instituto de Letras e Linguística, Universidade Federal de Uberlândia, Uberlândia.

PAULINO, Graça (2013). "Formação de leitores: a questão dos cânones literários". In: GAMA-KHALIL, Marisa Martins; ANDRADE, Paulo Fonseca (Orgs.). As literaturas infantil e juvenil... ainda uma vez. Uberlândia: GPEA:CAPES, p.11-25.

PETIT, Michèle (2010). A arte de ler - ou como resistir à adversidade. São Paulo: Editora 34.

Thyago Madeira França é Doutor em Estudos Linguísticos e Mestre em Estudos Linguísticos pela Universidade Federal de Uberlândia. Lato Senso em Linguagens e Práticas de Ensino. É docente do curso de licenciatura em Letras e da Pós-Graduação Produção: Pesquisa e publica nas áreas de Ensino de Literatura, Letramento Literário, Literatura Brasileira e Análise do Discurso na Universidade Estadual de Goiás - Câmpus Sudeste. É 2o líder do Laboratório de Estudos Polifônicos (UFU) e pesquisador do Grupo de Pesquisa "A narrativa ficcional para crianças e jovens: teorias e práticas" (UERJ)

Email: thyago.franca@ueg.br

ORCID iD: http://orcid.org/0000-0002-7690-9611 